\title{
Heat Transport Study of the Laminar Heat Pipe Heat Exchanger
}

\author{
Wei-Keng Lin ${ }^{1}$, Ke Chine Liaw ${ }^{2}$, Min-Zen Tsai ${ }^{2}$, Min-Gung Chu ${ }^{2}$ \\ ${ }^{1}$ Engineering \& System Science Department, National Tsing Hua University, Hsinchu, Chinese Taipei; ${ }^{2}$ Tairone Energy Saving \\ Technology Co., Ltd., Taoyuan, Chinese Taipei. \\ Email: wklin@ess.nthu.edu.tw
}

Received August 17 ${ }^{\text {th }}, 2012$; revised September 26 ${ }^{\text {th }}$, 2012; accepted October $4^{\text {th }}, 2012$

\begin{abstract}
The purpose of this experiment is to analyze the performance of the Laminar Heat Pipe Heat Exchanger. The test samples were divided two groups, one is the metal corrugated sheet with heat pipe, and the other is the metal corrugated sheet only. By dipping these two group samples into hot water and to see the thermal image by Infrared thermal imager. The results shown the temperature risen of the sheet with heat pipe was faster than that of the sheet without heat pipe. In addition, the bigger of the temperature difference between hot water temperature and ambient temperature, the quicker of the temperature risen for the metal corrugated sheet, and the temperature of the metal corrugated sheet were homogenous as well. For example, when the water temperature is $30^{\circ} \mathrm{C}$, ambient temperature is $20^{\circ} \mathrm{C}$, the metal corrugated sheet with heat pipe rise rapidly to $26^{\circ} \mathrm{C}$ within 1 minute, while the metal corrugated sheet without heat pipe rise to $22^{\circ} \mathrm{C}$ only, this temperature difference would be more obvious with the increasing of the hot water temperature. When the hot water temperature is up to $40^{\circ} \mathrm{C}$, the metal corrugated sheet with heat pipe rise rapidly to $31^{\circ} \mathrm{C}$ within 1 minute, while the metal corrugated sheet without het pipe is still rise up to $22^{\circ} \mathrm{C}$ only. When the hot water temperature is up to $50^{\circ} \mathrm{C}$, the metal corrugated sheet with heat pipe rise rapidly to $33^{\circ} \mathrm{C}$ within 1 minute, while the sheet without heat pipe still keep at $22^{\circ} \mathrm{C}$, the results shown the heat pipe affect the temperature rising speed is obvious, and it also implying heat pipe is a very important parameter for the heat transfer rate of the Laminar Heat Pipe Heat Exchanger.
\end{abstract}

Keywords: Heat Pipe; Heat Exchanger; Metal Corrugated Sheet

\section{Introduction}

The heat exchanger is the indispensable equipment for mass and heat transport. In the petroleum, chemical, light industry, pharmaceuticals, energy, industrial production, the low temperature fluid need heat to high temperature fluid or conversely make the high temperature fluid turn to the low temperature fluid. All these processes would be achieved the energy transfer through liquid vaporization or vapor condensation. The medium of the heating or the condense process could be used gas to gas or liquid to gas. A variety of currently available heat exchanger classification can be divided into reversible (Recuperator), regenerative (Regenerator) and direct contact (Direct Contact Exchanger) [1]. The first type is Recuperator heat exchanger, Figure 1, heat is transfer from point B directly flow to point A through a thermal interface material. The common Recuperator heat exchanger include the air-cooled heat exchanger (Figure 2), shell and tube heat exchanger (Figure 3) [2] and the plate heat exchanger (Figure 4) [3,4]. Since the heat transfer for the first type Recuperator heat exchanger, must pass through the interface, in order to improve the efficiency of the transmission, the materials used in heat exchangers is chosen the principle of material of high conductivity $(\kappa)$ such as $\mathrm{Cu}(\kappa=386 \mathrm{~W} / \mathrm{m} \cdot \mathrm{K})$ and Aluminum $(\kappa=204 \mathrm{~W} / \mathrm{m} \cdot \mathrm{K})$. The second type is the same as Recuperator heat exchanger, it through a working interface to transfer heat, but the transfer of heat does not occur at the same time, the heat transport mechanism shown as in Figure 5, the fluid A passing through the interface material within time (A). In the mean time, the heat is not releasing from the interface material until the fluid B passing through that interface material within time $\mathrm{B}$, the energy is then complete transport from fluid A to fluid B, Rotary heat exchanger is the most famous example [5]. The third type of heat exchanger for direct contact heat exchanger, the transfer of heat by direct (or partial direct) contact with two working fluids. Cooling towers is a well-known example, even if the two working fluid is passed through direct contact with each other to achieve the energy transfer, but in the true operation, there is still need the base material and the flow guides to 


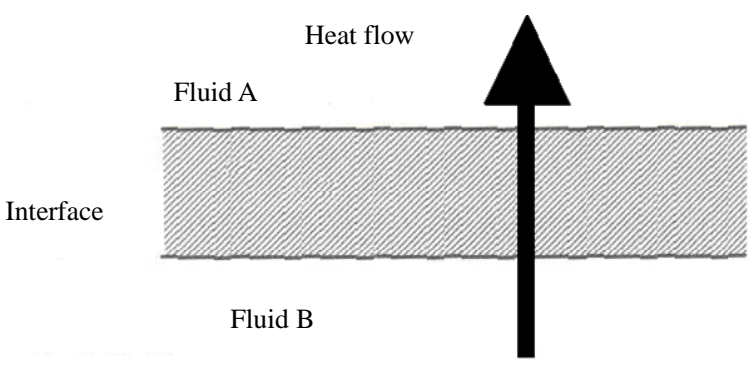

Figure 1. Operation principle of the recuperator heat exchanger.

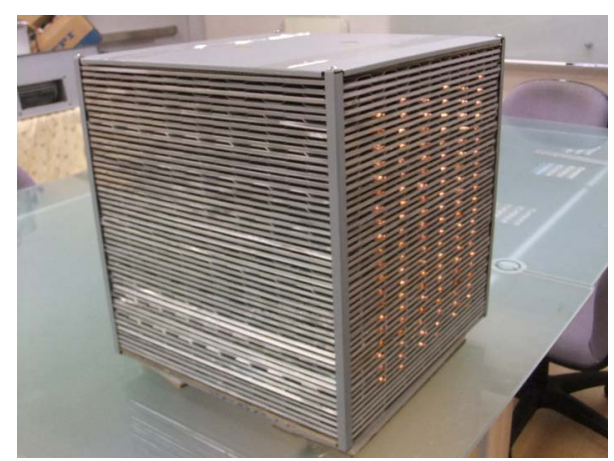

Figure 2. Air-cooled heat exchanger.

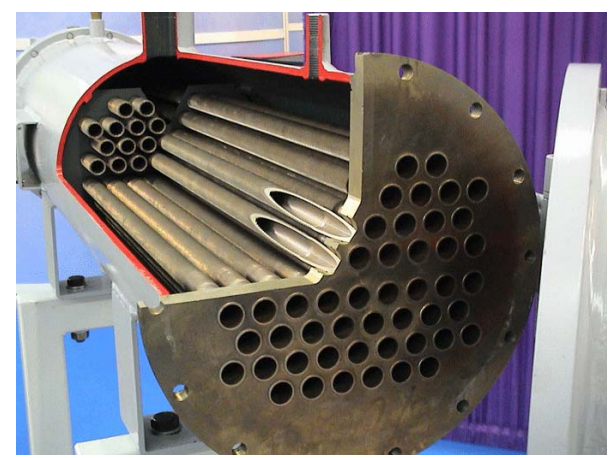

Figure 3. Shell and tube heat exchanger.

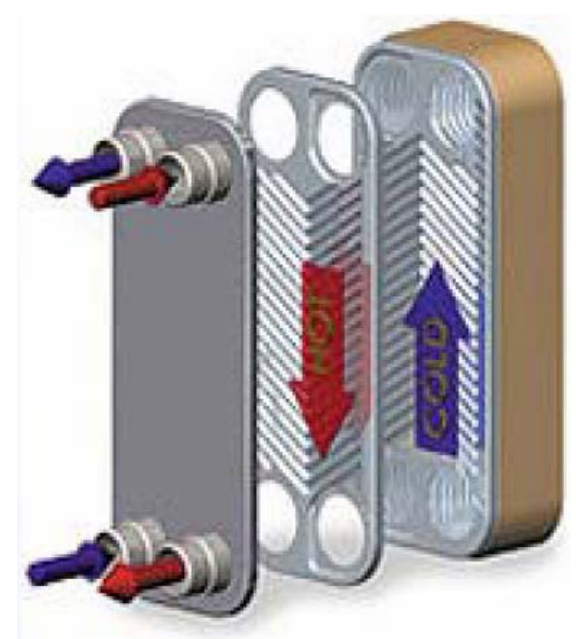

Figure 4. Plate heat exchanger.
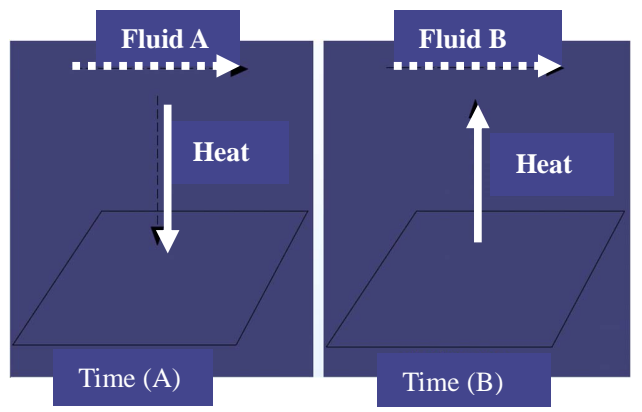

Figure 5. Operation principle of regenerative heat exchanger.

improve the mixing rate and mixing time of the fluid and thus result in the high heat transfer efficiency [6].

\section{Operation Theory}

In this study, we are focus on the air cooling heat exchanger which is belonged to Recuperator heat exchanger type. The developed product in this study is to insert several heat pipes into the metal corrugated sheet namely "Laminar Heat Pipe Heat Exchanger". The operation theory is as shown as in Figure 6, the gas in the indoor side is insulated from the gas in the outdoor side, and therefore, the gas flow is only taken away heat and not hybrid with the outdoor side gas and cause air pollution of the indoor air. The purpose of the heat pipe is to accelerate the heat conductance rate and achieve the temperature of the metal corrugated sheet homogeneous. The heat pipe is adhesive with the metal corrugated sheet as shown in Figure 7. In general, the heat conductivity of the heat pipe is 1000 times than that of the solid copper rod; therefore, the heat transport rate is 1000 time of the solid copper rod as well. It also implying when the heat pipe absorb heat at the evaporator section, the heat would be transported to the condenser section following the axial direction immediately. The high temperature vapor is released the heat in the condenser section and then turned out to be liquid form again and flow back to evaporator by the capillary force of the wick. When the heat pipe is transported heat from one side to another side periodically, the thermal energy is also transported to from heat pipe to metal corrugated sheet, therefore, the sheet obtained the heat very quickly as well.

\section{Experiment and Procedure}

The test two samples were shows as in Figure 8, the metal corrugated sheet is $400 \times 400 \mathrm{~mm}$, several $3 \times 3 \times$ $410 \mathrm{~mm}$ heat pipe were inserted into the metal corrugated sheet. The sample group which is no heat pipe namely "N-type", while the group adhesive with heat pipe namely "W-type". For the sake of the thermal image resolution, these two group metal corrugated sheets were 


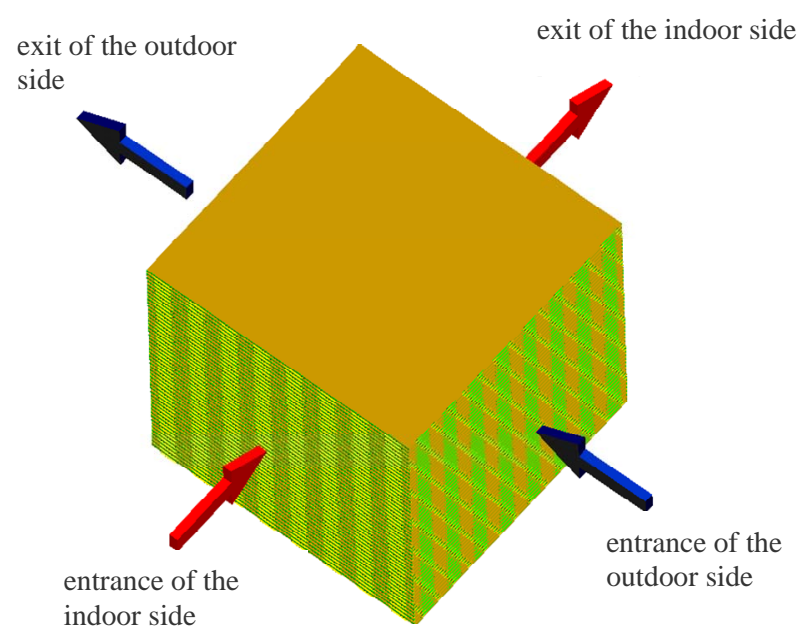

Figure 6. Operation principle of laminar heat pipe heat exchanger.

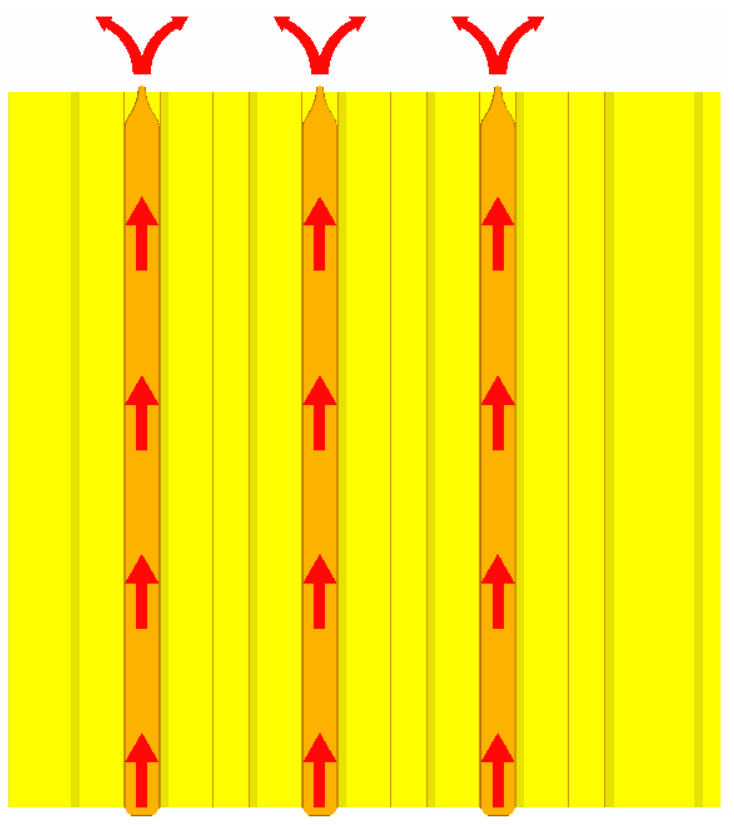

Figure 7. Orientation of the heat flow for the heat pipe in the corrugated sheet.

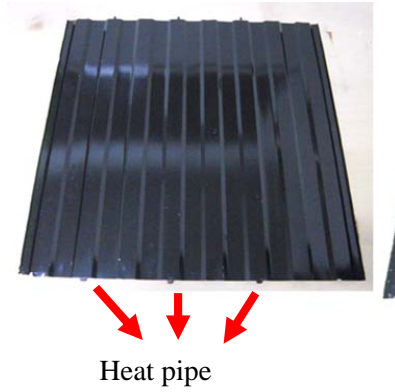

(a)

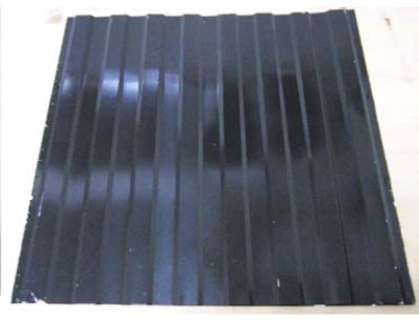

(b)
Figure 8. Metal corrugated sheet samples. (a) The metal corrugated sheet with Heat pipe (W-type); (b) The metal corrugated sheet without Heat pipe (N-type). coated with black color. To keep the temperature of the hot water reservoir constant, a $300 \mathrm{~W}$ heating electrical spoon with a constant temperature controller was used to heating the water shown in Figure 9. The Infrared thermal imager in this experiment was ThermoPro TP-8 shown as in Figure 10, the thermal imager was used to observed the 2D temperature distribution.

When the experiment start, add the water to the assigned level position, heating electrical spoon was then start to heat the water until the water temperature up to the required temperature which were $30^{\circ} \mathrm{C}, 40^{\circ} \mathrm{C}$ and $50^{\circ} \mathrm{C}$. These two group metal corrugated sheets (W-type and N-type) were then dipped into the hot water reservoir with the same water level, Figure 11. In the meantime, another thermocouple was attached tightly on the surface of the other side of the metal corrugated sheet (cold side), recorded all the temperature distribution with respect to time.

\section{Results and Discussion}

There were three kinds of the test model in this experiment, which were $30^{\circ} \mathrm{C}, 40^{\circ} \mathrm{C}$ and $50^{\circ} \mathrm{C}$ of the hot water reservoir temperature. The test samples were $\mathrm{W}$-type and $\mathrm{N}$-type, the ambient temperature keep at $20^{\circ} \mathrm{C}$. The re-

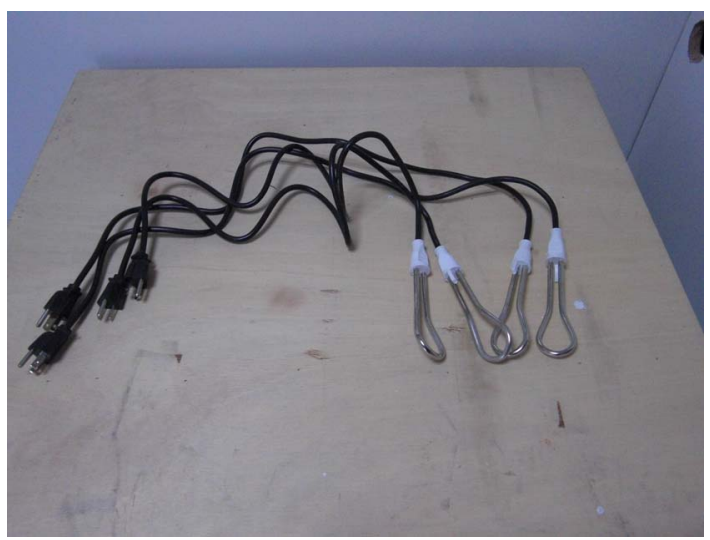

Figure 9. Heating electrical spoon.

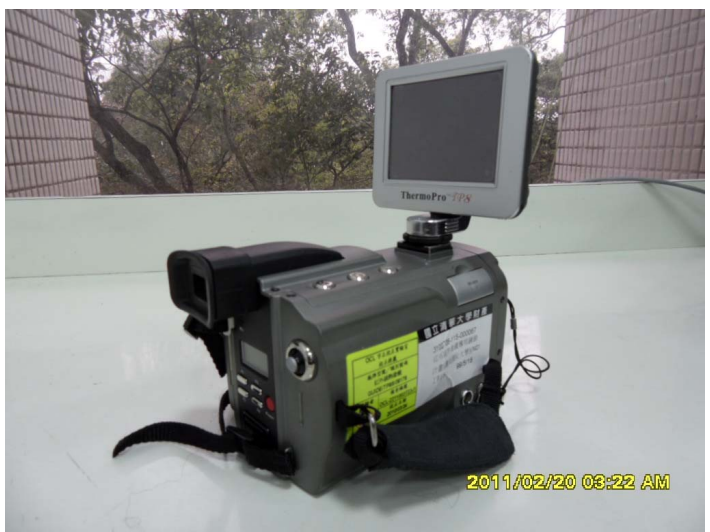

Figure 10. Infrared thermal imager. 


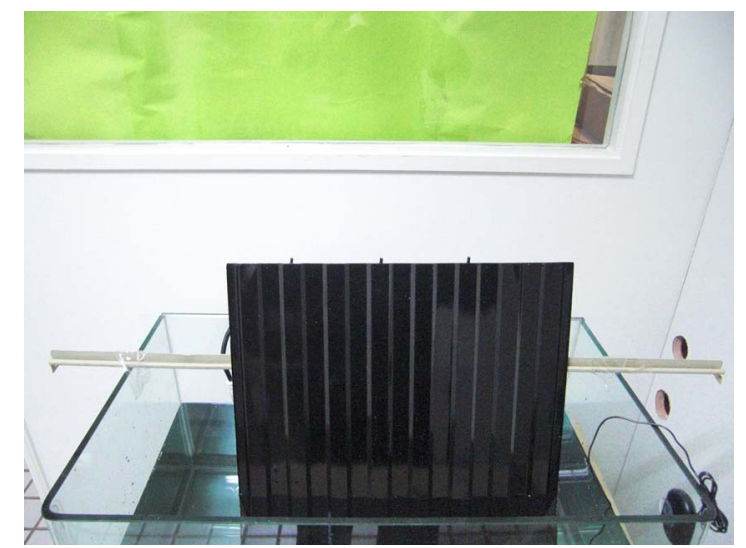

Figure 11. The metal corrugated sheet (W-type) with the hot water reservoir.

sults were discussed respectively as following:

Model 1: ambient temperature: $20^{\circ} \mathrm{C}$, water temperature: $30^{\circ} \mathrm{C}$, test time period: 60 seconds.

As in Figure 12, the initial thermal image of the $\mathrm{N}$-type at ambient temperature $20^{\circ} \mathrm{C}$, water temperature $30^{\circ} \mathrm{C}$. At time is zero, the cold side temperature (S1) of the metal corrugated sheet was $20.1^{\circ} \mathrm{C}$ which represented the thermal balance happened between metal sheet the ambient. After 60 seconds, Figure 13, the S1 temperature was up to $21.5^{\circ} \mathrm{C}$ and which was only $1.4^{\circ} \mathrm{C}$ difference compare with the initial temperature, it was also implying the temperature rising speed was very slow under the temperature difference $10^{\circ} \mathrm{C}$ between the water temperature and ambient temperature. The condition was completely changed when the metal corrugated sheet was inserted with heat pipe (W-type), Figure 14 shown the same test condition as in the Figure $\mathbf{1 3}$ but used the $\mathrm{W}$-type instead. The cold side temperature (S1) of the metal corrugated sheet was $20.7^{\circ} \mathrm{C}$ at the initial state, however, after 60 seconds, the $\mathrm{S} 1$ temperature was up to $25.5^{\circ} \mathrm{C}$, Figure 15, the temperature rising $4.8^{\circ} \mathrm{C}$ from the initial condition in this case. The result shown apparently that the $4.8^{\circ} \mathrm{C}$ temperature difference for the $\mathrm{W}$-type was faster than the temperature difference $1.4^{\circ} \mathrm{C}$ for the $\mathrm{N}$ type. Figure 16 show the comparison of the temperature rising between $\mathrm{W}$-type and $\mathrm{N}$-type at water $30^{\circ} \mathrm{C}$, the red line represented the temperature rising speed for the W-type, while the blue one represented the temperature rising speed for the N-type. The curve show the red one was faster than the blue one.

Model 2: ambient temperature: $20^{\circ} \mathrm{C}$, water temperature: $40^{\circ} \mathrm{C}$, test time period: 60 seconds.

As in Figure 17, the initial thermal image of the $\mathrm{N}$-type at ambient temperature $20^{\circ} \mathrm{C}$, water temperature $40^{\circ} \mathrm{C}$. When at time is zero, the cold side temperature (S1) of the metal corrugated sheet was $23.6^{\circ} \mathrm{C}$. Figure 18 showed the S1 temperature keep the same $23.6^{\circ} \mathrm{C}$ after 60 seconds, there was almost no temperature change in

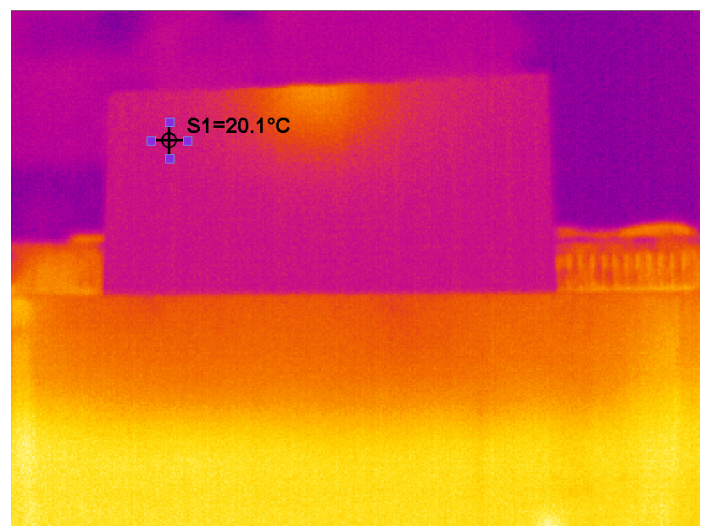

Figure 12. Ambient temperature $20^{\circ} \mathrm{C}$, water temperature $30^{\circ} \mathrm{C}$, (N-type) initial thermal image.

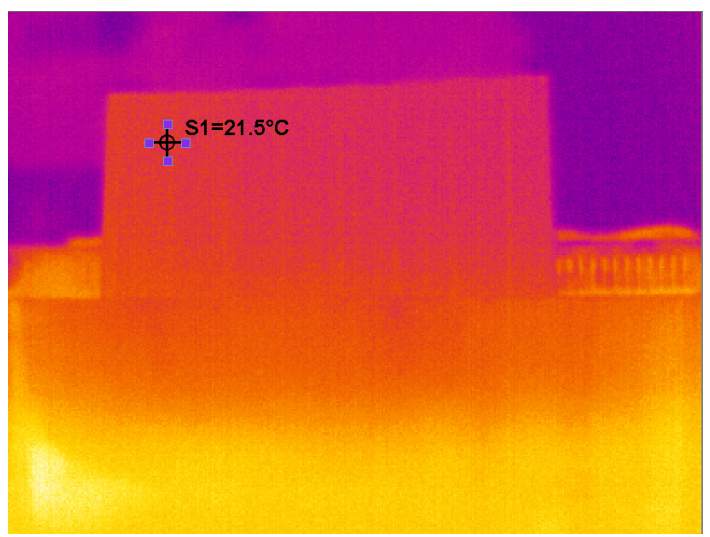

Figure 13. Ambient temperature $20^{\circ} \mathrm{C}$, water temperature $30^{\circ} \mathrm{C}$, (N-type) final thermal image after 60 seconds.

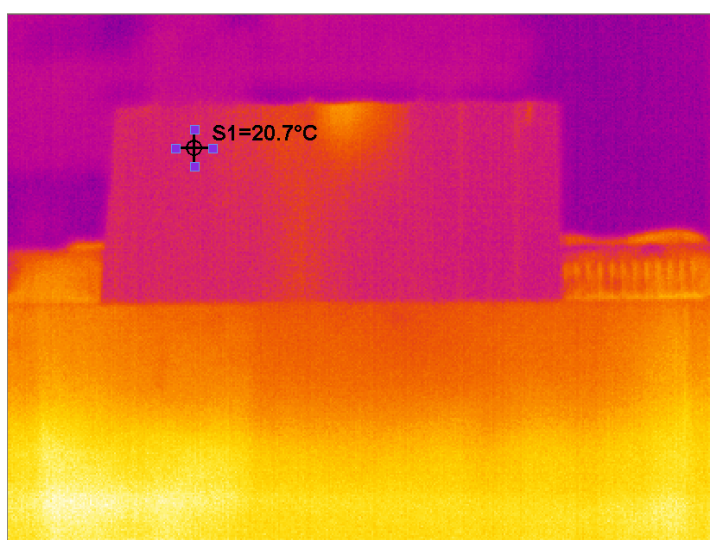

Figure 14. Ambient temperature $20^{\circ} \mathrm{C}$, water temperature $30^{\circ} \mathrm{C}$, (W-type) initial thermal image.

this case. Figure 19 showed the test condition for $\mathrm{W}$-type at the initial condition, the cold side temperature (S1) of the metal corrugated sheet was $21.7^{\circ} \mathrm{C}$. But after 60 seconds, the $\mathrm{S} 1$ temperature was up to $30.6^{\circ} \mathrm{C}$, Figure 20, the temperature rising $8.9^{\circ} \mathrm{C}$ from the initial condition. Figure 21 show the comparison of the temperature rising between $\mathrm{W}$-type and $\mathrm{N}$-type at water $40^{\circ} \mathrm{C}$, the red line 


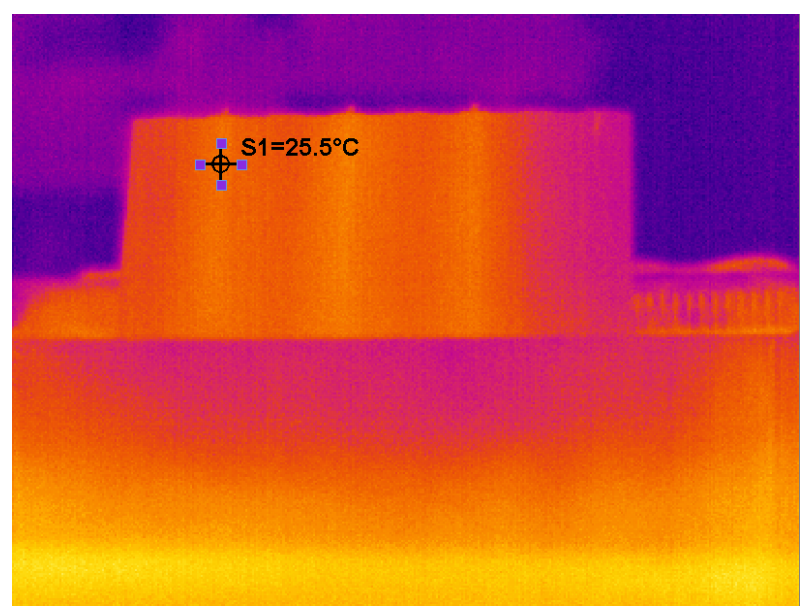

Figure 15. Ambient temperature $20^{\circ} \mathrm{C}$, water temperature $30^{\circ} \mathrm{C}$, (W-type) final thermal image after 60 seconds.

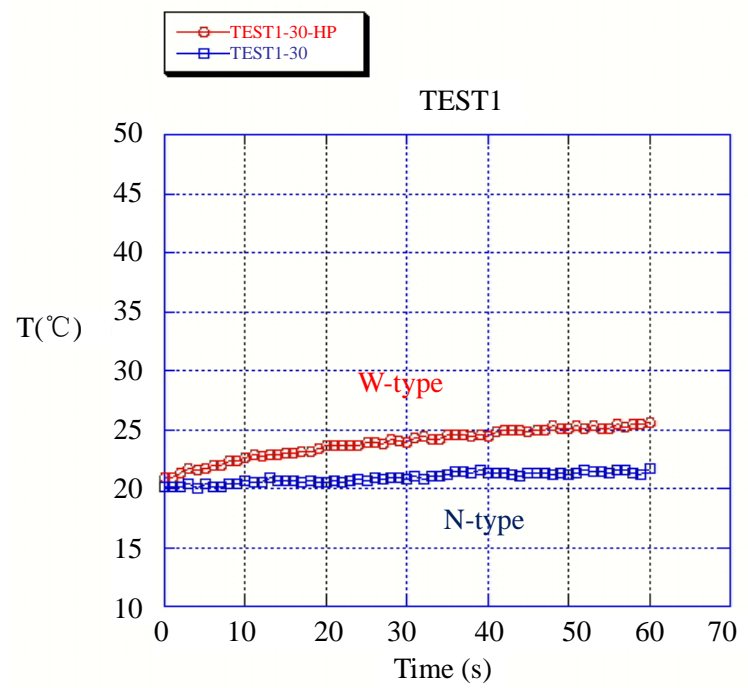

Figure 16. Comparison of the temperature rising between $\mathrm{W}$-type and $\mathrm{N}$-type at water $30^{\circ} \mathrm{C}$.

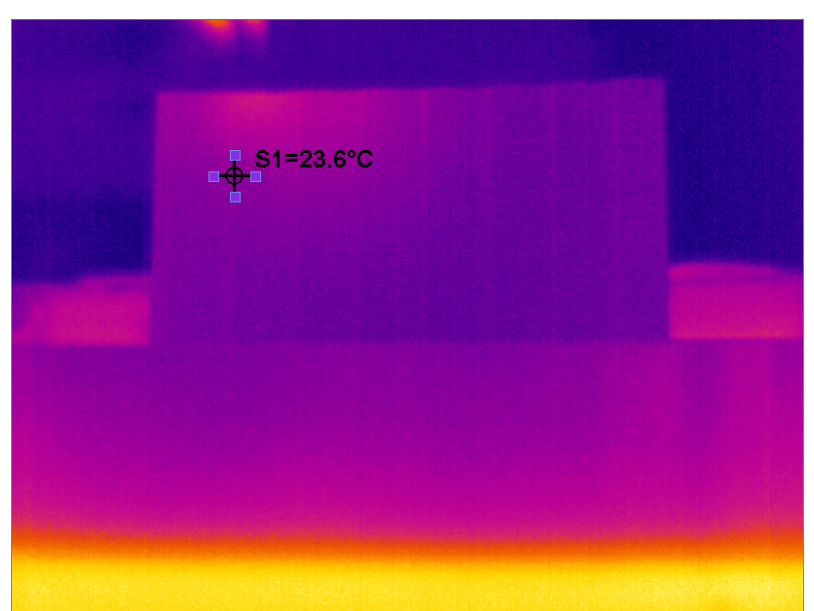

Figure 17. Ambient temperature $20^{\circ} \mathrm{C}$, water temperature $40^{\circ} \mathrm{C}$, (N-type) initial thermal image.

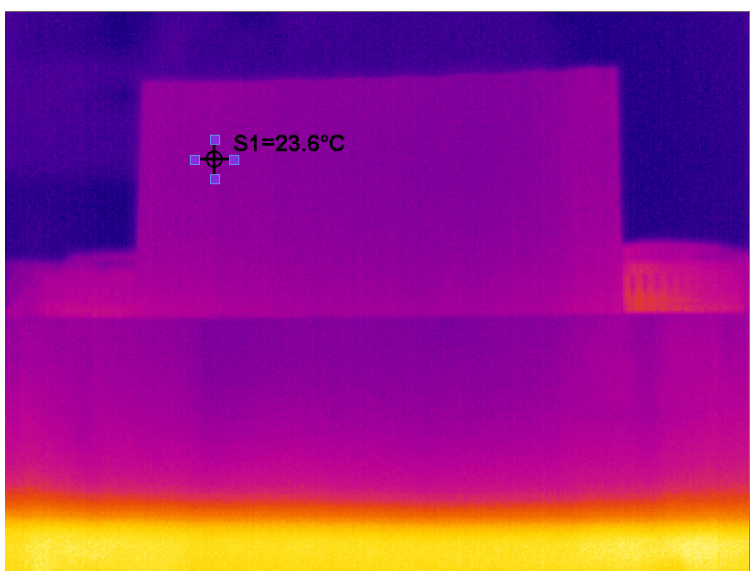

Figure 18. Ambient temperature $20^{\circ} \mathrm{C}$, water temperature $40^{\circ} \mathrm{C}$, ( $\mathrm{N}$-type) final thermal image after 60 seconds.

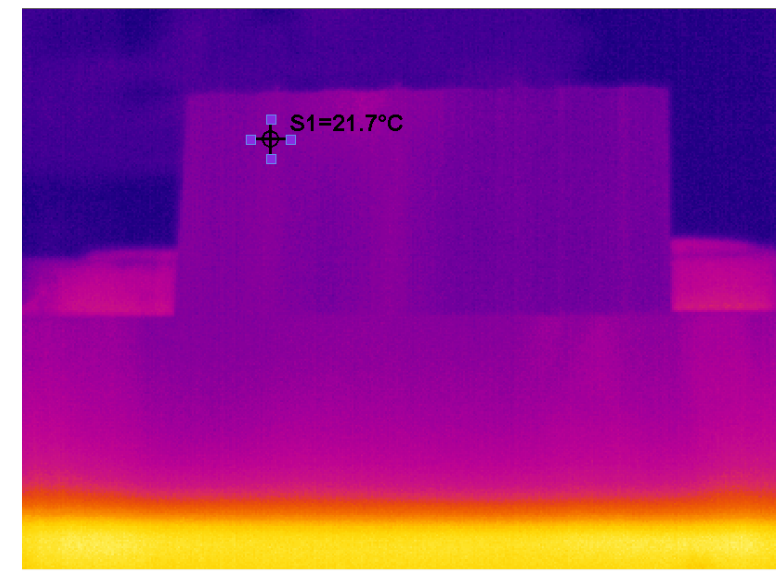

Figure 19. Ambient temperature: $20^{\circ} \mathrm{C}$, Water temperature: $40^{\circ} \mathrm{C}$, (W-type) initial thermal image.

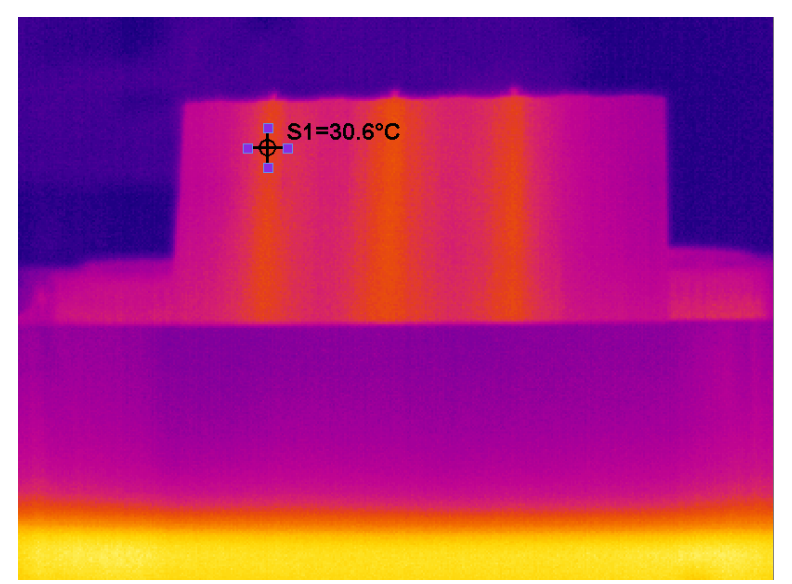

Figure 20. Ambient temperature: $20^{\circ} \mathrm{C}$, Water temperature: $40^{\circ} \mathrm{C}$, (W-type) final thermal image after 60 seconds.

represented the temperature rising speed for the $\mathrm{W}$-type, while the blue one represented the temperature rising speed for the N-type. The curve show the red one was faster than the blue one. 


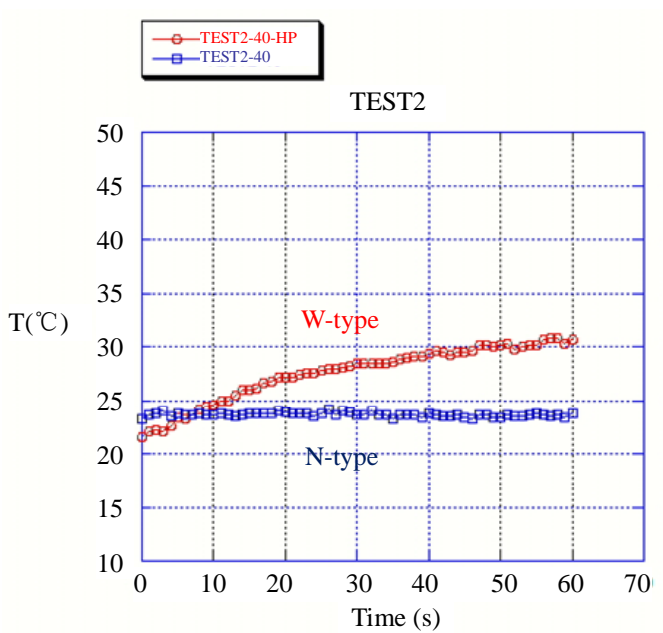

Figure 21. Comparison of the temperature rising between $\mathrm{W}$-type and $\mathrm{N}$-type at water $40^{\circ} \mathrm{C}$.

Model 3: ambient temperature: $20^{\circ} \mathrm{C}$, water temperature: $50^{\circ} \mathrm{C}$, test time period: 60 seconds.

As in Figure 22, the initial thermal image of the $\mathrm{N}$-type at ambient temperature $20^{\circ} \mathrm{C}$, water temperature $50^{\circ} \mathrm{C}$. When at time is zero, the cold side temperature (S1) of the metal corrugated sheet was $20.2^{\circ} \mathrm{C}$, there was almost no temperature change in this case again. Figure 23 showed the $\mathrm{S} 1$ temperature was up to $23.3^{\circ} \mathrm{C}$ after 60 seconds and there is only $3.1^{\circ} \mathrm{C}$ difference only. Figure 24 showed the test condition for W-type at the initial condition, the cold side temperature (S1) of the metal corrugated sheet was $21.6^{\circ} \mathrm{C}$. But after 60 seconds, the $\mathrm{S} 1$ temperature was up to $32.8^{\circ} \mathrm{C}$, Figure 25, there was $11.2^{\circ} \mathrm{C}$ temperature difference compare with the initial condition. The temperature rising speed $11.2^{\circ} \mathrm{C} / \mathrm{min}$ at water temperature $50^{\circ} \mathrm{C}$ was also almost three times the speed $4.8^{\circ} \mathrm{C} / \mathrm{min}$ when water at $30^{\circ} \mathrm{C}$. Figure 26 show the comparison of the temperature rising between $\mathrm{W}$-type and $\mathrm{N}$-type at water $50^{\circ} \mathrm{C}$, the red line represented the temperature rising speed for the $\mathrm{W}$-type, while the blue one represented the temperature rising speed for the $\mathrm{N}$-type. Obviously, the curve show the red one was faster than the blue one.

\section{Conclusions}

1) The temperature rising speed for the metal corrugated sheet with heat pipe was faster than that of the metal corrugated sheet without heat pipe. The reason was that the heat pipe would accelerate the heat flow speed along the axial coordinate.

2) When at constant ambient temperature, the bigger of the temperature different between the hot water temperature and ambient temperature, the faster of the temperature rising for the cold side temperature of the metal corrugated sheet, the more important of the heat pipe

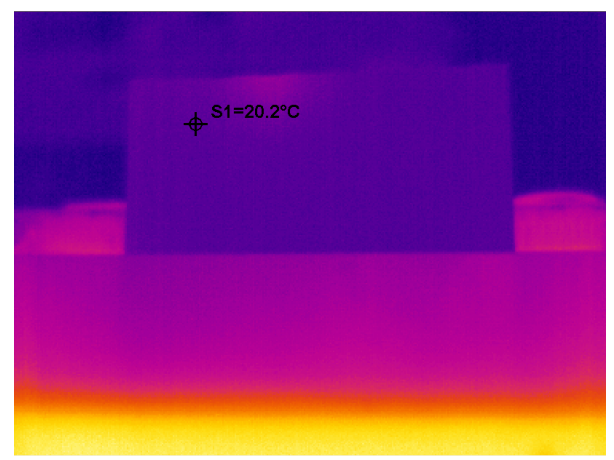

Figure 22. Ambient temperature: $20^{\circ} \mathrm{C}$, Water temperature: $50^{\circ} \mathrm{C}$, (N-type) initial thermal image.

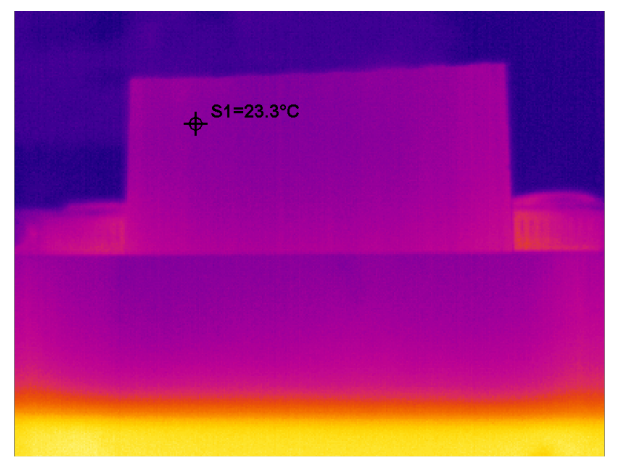

Figure 23. Ambient temperature: $20^{\circ} \mathrm{C}$, Water temperature: $50^{\circ} \mathrm{C}$, ( $\mathrm{N}$-type) final thermal image after 60 seconds.

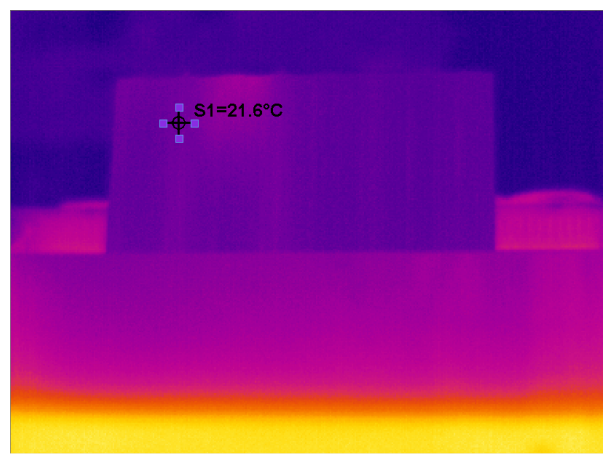

Figure 24. Ambient temperature: $20^{\circ} \mathrm{C}$, Water temperature $50^{\circ} \mathrm{C}$, (W-type) initial thermal image.

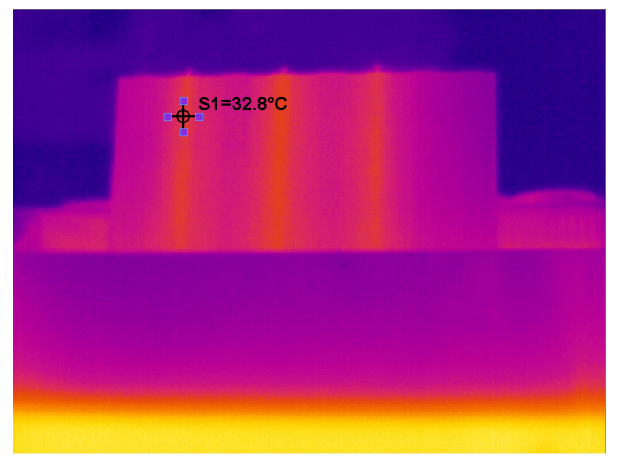

Figure 25. Ambient temperature: $20^{\circ} \mathrm{C}$, Water temperature: $50^{\circ} \mathrm{C}$, (W-type) final thermal image after 60 seconds. 


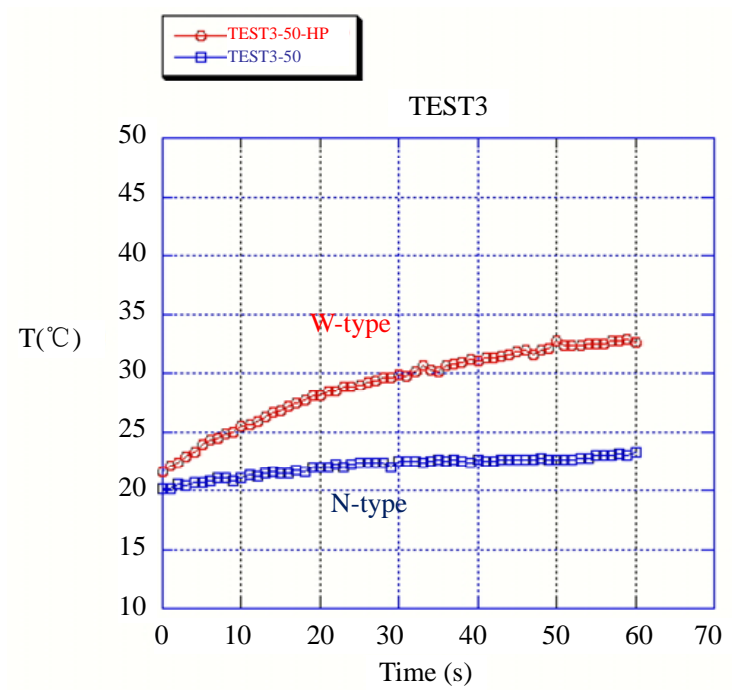

Figure 26. Comparison of the temperature rising between $\mathrm{W}$-type and $\mathrm{N}$-type at water $50^{\circ} \mathrm{C}$.

characteristic, Figure 26 give the apparently example for the water temperature at $50^{\circ} \mathrm{C}$.

3) For the case of the metal corrugated sheet with heat pipe, the sheet surface temperature would be more homogeneous shown as in Figures 15, 20 and 25. The reason why cause the surface temperature homogeneous was that the heat pipe not only transfer the heat following the axial direction of the sheet, but also spreading the heat to the $\mathrm{X}$-Y direction of the sheet as well, thus result in the temperature of the surface of the sheet homogeneous.

\section{Acknowledgements}

This project (NSC-100-2622-E-007-006-CC2) is sponsor by Tairone Energy Saving Tech. Co., Ltd., The metal corrugated sheet provider, without their help, the experiment can't be carried out so smoothly completed.

\section{REFERENCES}

[1] C. C. Wang, "Heat Exchanger Design,” Wu-Nan Publication Co., Taipei, 2007.

[2] D. B. Chang, "Heat Transfer Performance Enhancement of Shell and Tube Evaporator," Lectures in Nan-Tai University of Science and Technology, 2007.

[3] J. P. Holman, “Heat Transfer,” McGraw-Hill, New York, 1990.

[4] G. F. Hewitt, "Executive Editor,” Heat Exchanger Design Handbook, Begell House Inc., New York, 2002.

[5] S. Kakac and H. Liu, "Heat Exchangers," CRC Press Ltd., London, 2002.

[6] W. M. Rohsenow, J. P. Heartnett and Y. I. Cho, "Handbook of Heat Transfer,” McGraw-Hill, New York, 1998. 